\title{
Creating School Scientific Communities Among Urban Refugee ELL Populations
}

\author{
Joseph A Johnson ${ }^{1}$, Mihwa Park 2* \\ ${ }^{1}$ Department of Physics, Mercyhurst University, Erie, PA, USA \\ ${ }^{2}$ Department of Curriculum and Instruction, College of Education, Texas Tech University, Lubbock, TX, USA \\ * Corresponding author: Mihwa.Park@ttu.edu
}

Received: 24 Sep. $2021 \bullet$ Accepted: 9 Nov. 2021

Citation: Johnson, J. A., \& Park, M. (2022). Creating School Scientific Communities Among Urban Refugee ELL Populations. European Journal of Science and Mathematics Education, 10(1), 87-103. https://doi.org/10.30935/scimath/11380

\begin{abstract}
:
Studies on English language learners (ELLs) and school science have been conducted from a range of theoretical and disciplinary perspectives, the findings of which have indicated growth in science achievement among ELLs when exposed to science inquiry. Yet studies are still needed to address the needs of specific groups within this large, and growing population. Children who are underserved in schools offering limited ELL support continue to be marginalized, and the gap for their future professional and higher education opportunities continues to grow when compared to their majority peers. Teachers often lack the experience, knowledge, and institutional support needed to address the complex educational needs of ELLs. The goal of this study was to examine aspects of multimodal science inquiry teaching strategies using technology with a specific group of students learning English as a new language. This paper describes a qualitative, autoethnographic, case study with three students from the Karen and Karenni cultures, coming to the United States from three different refugee camps in Thailand. Multiple data sources were collected throughout an year-long study, including videos of lessons, recorded focus groups, student artifacts, researcher field notes and reflections, and interviews with the classroom teachers. We coded data as emerging themes iteratively using HyperResearch qualitative research software. The study demonstrated how refugees ELL students developed their discourse skills and classroom engagements through the yearlong intervention designed to build trust between teacher and students by sharing responsibility for practice and learning, to involve inquiry-based science activities, and to value students' communities and culture. The study was founded on the premise that students of diverse linguistic and cultural backgrounds can participate effectively in scientific inquiry.

Keywords: ELL, refugee, multimodality, inquiry
\end{abstract}

\section{INTRODUCTION}

She's forgotten. These kids are the forgotten kids. These are the quiet kids that the teachers are like "Oh we are so happy they are here because they are so quiet and they are not causing any trouble." Comment from Aid Working in the Classroom

This quote, from a teaching aid working in the school where this study took place, describes a larger problem faced by content teachers tasked with teaching English language learners. Teachers are asked to address the educational needs of students who are acquiring the language and culture of mainstream United States society, while also learning the norms, content, and processes of academic disciplines (Arkoudis, 2003; Lee, 2005) and these teachers are often meeting limited success. Research has demonstrated the consistent inequitable achievement between ethnically and linguistically diverse students in school (Gay, 2000; Lee, 2005). Specifically, Lopez (2010) found differences in academic achievement between English language learners (ELLs) and non-ELL students in the US National 
Assessment of Educational Progress results (NAEP). Jiménez-Castellanos and García (2017) also noted persistent achievement gaps for ELL students, as well as underfunded and unsafe schools and high rates of poverty. These gaps indicate a major failing nationally in meeting the needs of this group of students.

The goal of the study was to examine aspects of multimodal science inquiry teaching strategies, using technology, applied in teaching this specific group of students learning English as a new language and to develop instructional methods to engage them in science in meaningful ways. As such, both the researchers and students had to navigate the complex interconnections between science education for English language learners, integration of technology, and working with refugee populations, each of which is explored in greater depth in the literature review below. The following question guided the study: In what ways, if any, does attention to multimodal technology-enhanced inquiry practices assist refugee, English language learners in learning science in an urban context?

\section{Equity in Teaching English Language Learners}

Over the past few decades, research has shown that the population of students in the United States has become increasingly linguistically and culturally diverse (Lee \& Buxton, 2013; Villegas et al., 2018). Given that these demographic shifts in the U.S. indicate that the number of English language learners enrolling in schools will continue to increase, a clearer understanding of how these students adapt to face the overwhelming tasks of being students in a new language and cultural context is of national concern (Iddings \& Jang, 2008), particularly in light persistent achievement gaps across content areas (Lee \& Buxton, 2013; Llosa et al., 2016).

Unfortunately, teachers often lack the experience, knowledge, and the institutional support needed to address the complex educational needs of ELLs (Lee, 2005). Further, to successfully meet current standards, ELLs will need both science content and English language instruction to develop contentspecific discourse and literacy skills (Lee \& Buxton, 2013). Reform aimed at academic achievement of ELLs requires knowledge of academic disciplines as well as knowledge of English language and literacy development. It often falls on classroom teachers integrate these two kinds of knowledge (Lee, 2005). Yet science education outcomes, including standardized test scores, meaningful learning of classroom tasks, attitudes, interest, motivation, course enrollment, high school completion, higher education, and career choices (Lee \& Luykx, 2007), play secondary roles to acquisition of English skills in determining science achievement (Lee, 2005). Educational policies and practices, moreover, do not generally support desired science outcomes with ELLs, nor do they substantially engage or incorporate the knowledge and practices that ELLs bring to science classrooms (Lee, 2005).

The majority of teachers working with ELLs do not believe that they are adequately prepared to meet students' learning needs, particularly in academically demanding subjects such as science (Janzen, 2008). In instances where ELLs are in mainstream classes, they are confronted with the need to develop their subject specific knowledge and English proficiency simultaneously (Arkoudis, 2003; Lee \& Buxton, 2013). Unfortunately, science instruction typically has failed to help ELLs learn science in ways that are meaningful and relevant to them, while also failing to help develop oral and written English proficiency (Lee, 2005). Compounding the cultural disparities is the fact that the rules of classroom discourse are often largely implicit and tacit, making it difficult for students who have not learned the rules at home to figure them out on their own (Gee, 2005; Michaels \& O'Connor, 1990).

Providing equitable learning opportunities requires that schools value and respect the experiences that ELLs bring with them to school and offer resources and funding to support their learning at levels comparable to those available for mainstream students (Gay, 2000; Lynch, 2000). Noddings (1997) calls to attention the importance of moving beyond a focus primarily on curricular objectives and towards caring for individual students, taking into account the unique characteristics and backgrounds that all students bring to the classroom. Investing this time in understanding students' perspectives can result in better teaching strategies and more effective schooling for traditionally marginalized students 
(McBrien, 2005). Once again, recognizing the cultural needs of the students and recognizing and adjusting the teacher's own cultural predispositions led to greater understanding and ultimately more success in the classroom.

\section{Science for English Language Learners}

Appropriate responses to assisting ELL students in learning science are proven teaching strategies where students are encouraged to make sense of science through experiences, manipulatives, technology, and research-driven inquiry methods (Glasgow et al., 2011; Lee, 2005; Oliveira et al., 2019; Rodriguez \& Kitchen, 2005; Tan \& Barton, 2010). The assumption that ELLs must acquire English before learning subject matter is extremely prevalent amongst teachers, despite the most probable outcome of such an assumption being that these students will fall behind their English-speaking peers (August \& Hakuta, 1997). Science instruction typically has failed to help ELLs learn science in ways that are meaningful and relevant to them, while also failing to help develop oral and written English proficiency (Lee, 2005). As stated, many new teachers do not feel sufficiently prepared to teach in academically demanding subjects such as science, especially at the elementary and middle school levels, and the majority of teachers working with ELLs do not believe that they are adequately prepared to meet learning needs of their language learners (Lee, 2005). The issue is further compounded since ELLs may not present behavioral problems, and thus their needs may go unnoticed. Yet, amid these various roadblocks, inquiry-based science instruction has been shown to provide an excellent context for developing both English and science proficiency simultaneously (Jarrett, 1999; Lee \& Buxton, 2013; Oliveira et al., 2019).

Inquiry-based science can provide "a rich environment for simultaneous cognitive and linguistic development" (Kessler \& Quinn, 1995, p. 97). Bransford and Donovan (2005) describe the essential components of science inquiry as including problem solving, answering meaningful questions, data/evidence-based decisions, collaboration, authentic problem solving, social interaction, use of specialized language, and use of specific representations and tools. In their study, Kessler and Quinn (1995) observed that problem solving provides "sociocognitive conflict" that facilitates the development of new language. Students are able to draw upon both languages, as they work with peers collaboratively, to solve meaningful problems, thereby allowing them to spend less energy on language, and to focus instead on the ideas and concepts being explored (Jarrett, 1999). Through inquiry, students are able to use familiar words as they developed their academic language skills and became more comfortable with classroom discourse (Oliveira et al., 2019).

Science inquiry is not dependent on formal mastery of English, instead promoting a variety of forms, or modes, of communication including written, oral, gestural, and graphic (Lee, 2005). The extensive use of graphics, explicit definitions for new terms, use of fairly simple syntactic structures, and clear directions for investigations all contribute to communication of meanings that is less linguistically demanding for ELLs (Kessler \& Quinn, 1995). Further, the collaboration and social interaction of science inquiry provide conditions of high motivation and low anxiety in which students build common experiences and feel more comfortable interacting to create meaning (Jarrett, 1999; Lee, 2005; Oliveira et al., 2019).

\section{Technology with ELLs}

For many years, educators have looked at technology as a potentially valuable resource for meeting the learning needs of ELL students (Lopez, 2010). Technological tools enable teachers to adjust and adapt classroom activities to better facilitate the language learning process (Ahmadi \& Reza, 2018). They can be a powerful method of increasing vocabulary and can be used to teach and assess component skills of literacy (August et al., 2009). Current software allows for a great deal of creativity, incorporating multimodal components and thus allowing greater flexibility for ELLs to learn in ways that they feel are relevant (Green, 2005). Further, technology has the potential to foster more learner-centered 
methods, facilitating a shift from more traditional, teacher-centered approaches (Ahmadi \& Reza, 2018). Effective use of technology "promotes learners' autonomy and helps them feel more confident, and increases learners' motivation to effectively learn a foreign language" (Ahmadi \& Reza, 2018, p. 122).

Liaw (1997) concluded that the use of a variety of language functions and the verbal interaction of English language learners can be facilitated by the use of the computer as a supplement to the traditional curriculum of the ELL classroom, promoting verbal communication and the acquisition of English. Yet technology resources guarantee effective pedagogy or language acquisition (Ahmadi \& Reza, 2018). It is important to note that it is not the technology itself, but the use of the technology to facilitate communication that is effective for the ELLs.

\section{Refugee Youth Students in the U.S.}

Many studies have reported a crisis of identity that both immigrant and refugee youth students are faced in school settings (Portes \& Rumbaut, 2001; Zhou \& Bankston, 2000). After substantial review of literature on refugees students in the U.S., McBrien (2005) concluded when refugees settled in highpoverty urban areas, "the youth often end up in a negative, subtractive assimilation pattern, rejecting their family and cultural ties in hopes of being accepted by American peers" (p. 355). Indeed, the majority of refugee students often enroll in high-poverty urban school settings (Cosentino de Cohen et al., 2005). Hos (2020) asserts that schools have a major influence on refugee youth students to become acclimated to new culture and language. The keys of their success are acquisition of new academic language and acceptance by their teachers and peers in their school settings (McBrien, 2005). In order to create more acceptance culture for refugee youth students in schools, teachers and administrators should increase their understanding of refugee experience; welcome their parents; and support them to retain their native language that helps to maintain their family and culture, which in turn supports their emotional well-being (McBrien, 2005). Further, Hos (2020) claimed that a specialized curriculum should be designed for refugee ELL students to develop their English language proficiency and content-area concepts simultaneously to support their academic success, because by the time that they acquired English proficiency, they might be way behind their peers in terms of knowledge of the content areas.

Although there were studies on how ELLs developed English and science proficiency simultaneously in science classrooms, at least when this study was conducted, there was no study on how a teacher and refugee ELL students were developing their practice and competency in science and language together. The study contributes to the body of literature by examining how the teacher developed his pedagogy to teach science to refugee ELL students, how refugee ELL students developed their science and English proficiency in science classrooms, and how they, the teacher and students, synchronously developed their practice and proficiency.

\section{METHODS}

This autoethnographic case study describes the first author's experience taking on the role of science teacher for a small group of 7th and 8th grade students who had been in the United States for less than a year, coming from Southeast Asia by way of refugee camps in Thailand. The students had been placed in what was identified as one of the poorest performing science classrooms within a large, urban school district. Prior to this intervention, these students were not struggling with scientific conceptual understandings or solving difficult problems as you might hope in a middle school science classroom. Instead, their profound disengagement and isolation from their class was noted as a stark contrast from the noise and confused activity of the rest of their class. Throughout this project, we enacted a model for science teaching that rested upon some fundamental tenets regarding: a) ELL instruction, b) inquirybased science content instruction, and c) technology. While other aspects were certainly important and impacted the teacher and student experiences, including education for refugee populations and in urban contexts, these constructs are beyond the scope of the current analysis. 


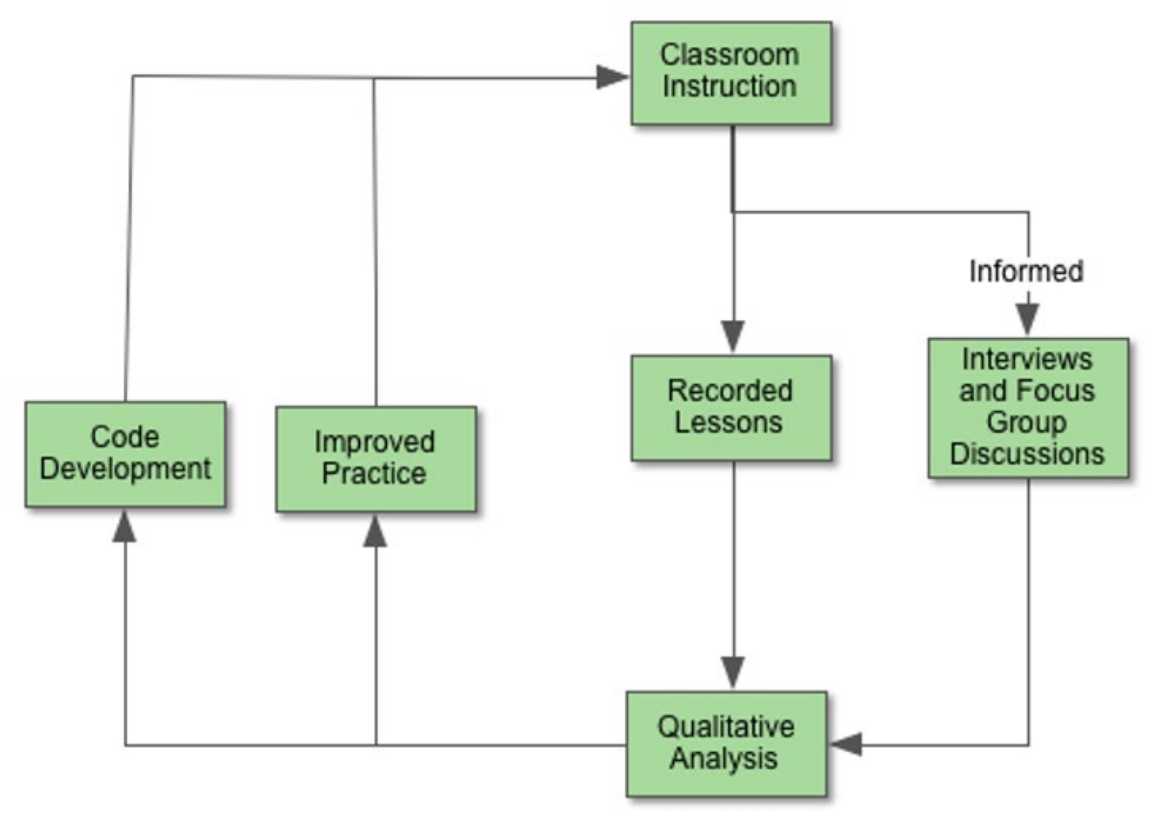

Figure 1. Research flow

Anderson (2006) described five components of autoethnographic research as complete member researcher (CMR) status, analytic reflexivity, narrative visibility of the researcher's self, dialogue with informants beyond the self, and commitment to theoretical analysis. As a CMR, the researcher has access to insider knowledge that would otherwise be impossible to gather. In the current study, the first author was immersed within the classroom working closely with participant students. For the autoethnographer, this introspective self-reflection is a legitimate focal point of the research (Wall, 2006). Reflexivity, has been described by Anderson as involving, "an awareness of reciprocal influence between ethnographers and their settings and informants. It entails self-conscious introspection guided by a desire to better understand both self and others through examining one's actions and perceptions in reference to and dialogue with those of others" (Anderson, 2006, p. 382). The case study analysis of classroom lesson video via HyperResearch qualitative research software was introspective in this way as it informed future classroom practice. Additionally, analysis of interviews and focus group discussions with participant students informed practice through dialogue with informants beyond the self. Codes were developed and refined with each round of investigation. Thus, analysis was iterative, initial assessments informing both future practice and analysis. Figure $\mathbf{1}$ shows the research flow from collecting data to analyzing them.

Regarding ELL instruction, our classroom practice was founded on leveraging the social, cultural, and linguistic tools that students brought with them to the classroom. The first author was involved in a research project as a research assistant, which allowed him to work with the refugee students who had been in the U.S. for less than a year. As a research assistant, he was able to take on the role of science teacher for the students in their science classrooms separately from the rest of the class, which was taught by their normal classroom teacher. Parents, community members, former students, and language experts should work collaboratively with science teachers to make central connections to content and the lives of children. In this way, equitable learning environments allow ELLs to develop academic science proficiencies in English as well as in their home language (Lee, 2005). Science content instruction methods shifted as the researchers learned and adapted to the needs of the group, however, the foundational principle centered on inquiry-based practices, ranging from guided to more open inquiry experiences (Banchi \& Bell, 2008).

Technological tools integrated were chosen based on the content being covered and on the researchers' growing understanding of what tools would best foster student interaction. These tools included digital sensors, digital video editing, "green screen" recording, the EarthBrowser app, and online simulations. 
This is consistent with the TPACK framework of teacher knowledge in that decisions regarding technology integration throughout the intervention were made based on the intersection of content knowledge, pedagogical knowledge, and growing knowledge of the students (Koehler \& Mishra, 2009).

\section{School and Classroom Context}

The school in which this study took place is located in a large urban school district in the northeastern U.S. The school had 48.39 classroom teachers, the decimal number indicating that some teachers split time between buildings and were only in this building part time. This gave the school a 10.27 student to teacher ratio. At the time of this study, the school was considered "under review" by the state department of education and was in danger of being shut down if test scores did not improve.

Mrs. Smith (pseudonym), the normal classroom teacher in the classroom where this study took place, a White, middle-aged woman, taught two classes in this building the last two periods of the day. She taught an eighth-grade life science class followed by a seventh-grade physical science class, spending her mornings in another school in the district. These classes had between fifteen and twenty students each day. She had been teaching science in the district for six years. Initially, the ELL students participating in this study were separated between the two classes. The eighth-grade students would leave science to attend a Spanish class. Fortunately, within the first week of the project the school allowed them to forego the Spanish class and remain in the science classroom for a double period with the first author and an ESL teaching aid, Ms. Crystal, working in the school through an independent agency. While she was there to work with younger students, her afternoons were free, so she would sit in to work with the seventh and eighth grade students on science lessons.

\section{ELL Support}

In reality, the English as a Second Language (ESL) support within the school consisted of one ESL teacher, responsible for both push-in and pull-out programs for over thirty students across grades $\mathrm{K}$ through eight. A Burmese (not the first language of any of my students) translator, Mrs. B, was available three days out of a six-day cycle, but she generally worked with younger students. Further, three of the participating students were from Burma, they spoke Karen and Karenni as first languages, not Burmese. Further, while it is true that providing an equitable educational experience "requires the collaboration and shared responsibility of staff at all levels," this was not how things played out within the school. No training was provided for content teachers, several of whom reported feeling overwhelmed and unable to adequately provide for this group while also struggling with the remainder of the class. Conversely, while the ESL staff did have the training for working with language learners, they had limited content knowledge, particularly in science, and could aid little in the students' acquisition of content knowledge.

\section{Research Participants}

Participating students included five students in seventh and eighth grade who, at the time of the study, had been in the U.S. for less than a year, coming from Burma by way of refugee camps in Thailand. The three students central to the current study, from the Karen and Karenni cultures, came from three different refugee camps in Thailand, at which they had spent the majority of their lives. Pseudonyms were used for each student. Luiza, an eighth grade student, was the quietest of the students. She was of Karenni culture and spoke the Karenni language as her first language and learned some Burmese to help communicate with others in the school. Da Po, another eighth grader, of Karen culture, spoke Karen as her first language and also learned some Burmese after leaving the refugee camp. She was a very diligent student enjoying mathematics and science class. Da Po was thinking about being an interpreter to help in the Karen community, or a scientist, or an astronaut. Lo Eh, in seventh grade, was the youngest student in the group. She was very enthusiastic and expressive during science lessons. Being the youngest, she often got "volunteered" by the others but seemed to be happy to participate. She was also Karen and spoke only the Karen language. Upon their arrival, several of the students' exact 
age was unknown. They were placed in seventh and eighth grade based on an estimate of their age by district administration. The three who spent the entire school year in the classroom were the primary focus of this study.

\section{Research Design for Data Collection and Analysis in Science/Technology}

We maintained an ethnographic methodology that rested upon teacher reflection and inquiry teaching (Creswell \& Poth, 2018). A general list of major content topics covered during this study, selected from the district mandated curriculum pacing guides for $7^{\text {th }}$ and $8^{\text {th }}$ grade (i.e., Motion graphing, body systems, microscopes, cells and cell parts, anatomy, magnets, temperature, cloud types, and weather). In this study, we focus on three selected critical incidents, identified by the researchers and member checked by the participants, that showed clear transitions of students' engagement and shifts in teacher pedagogy.

Multiple data sources were collected throughout this year-long study, including videos of lessons, recorded focus groups, student content exams, student artifacts (both digital and written), letters from participants' parents, and interviews with the classroom teacher, ESL teacher, and ELL teaching aid. Interviews were semi-structured and took place after school hours at the beginning and end of the school year.

Focus group sessions took place during an after school program that all participant students took part in three days per week. These group discussions involved the first author, each participant student, and a former student from the same science class the previous year who served as translator. Discussions occurred monthly and were video recorded. Conversations were student driven, providing an opportunity for students to inform the topics and teaching strategies employed and provide feedback to the researcher.

Student artifacts collected included lab reports, journals, science notebooks, and video projects. HyperResearch ${ }^{\circledR}$ qualitative research software (ver. 2.8.3) was used to organize, catalogue, and analyze transcription and video data, providing a digital record for retracing. Coding of data was done iteratively, each round of coding informing the next as themes emerged. For this paper we analyzed the teaching of the first author through reflection and analysis of recorded lessons from throughout the intervention in which he attempted to integrate inquiry-based teaching strategies with a group of students learning English as a new language. Additional data sources were used for triangulation of findings. Specifically, three critical incidents, identified during interviews as important points in the intervention, were analyzed in this study.

\section{FINDINGS}

To answer the research question, we organized the findings into three themes representing how the refugee ELL students developed their competence in science class as the intervention was implemented: (1) Initial Pedagogical Perspective, (2) Shifting Pedagogy, Shifting Discourse, and (3) From Silence to Science. Each theme captures characteristics of enacted lessons for interventions and students' engagements and discourses in the intervention class. Together, the three themes provide insight into how the students build trust with teacher/researcher and develop their engagements and discourse skills in the class.

\section{Initial Pedagogical Perspective}

The students entered into the context of American school unfamiliar with the established classroom norms and developed coping mechanisms in their attempts to navigate their daily school lives. While they come from a rich cultural background, that the authors were granted some access to, their culture was entirely ignored in their daily school experience. Their coping mechanisms were observed in each of their classes throughout the day, centered around obedience and passivity, the result being that they are effectively ignored in the classroom. These observations were supported by students and the 
teacher's aid. When they attempted to apply these strategies and coping mechanisms to our inquiry class, they found them inconsistent and unhelpful. Unfortunately, the appropriate discourse norms to participate in inquiry-based science lessons had yet to be developed, leaving them wondering what to do. School in this building, for these students, primarily consisted of sitting silently or at most copying what they saw on a board or filling in worksheets that they did not understand. In describing the students' school day, Ms. Crystal, a teaching aid, said:

Throughout the day in their different classes, they are so used to just copying whatever's being [written], even if they have no clue what they're copying. I remember actually at the beginning, when Mrs. Smith would put something, like a slide, they would copy every single word of the slide, even if it was a ridiculously long slide. Even if they didn't have to cause they felt compelled to copy, just like they feel compelled to draw, or whatever because that's all that they are used to doing all day.

Students would copy notes provided by the classroom teacher that they did not understand simply because that is what they believed they were supposed to do. Copying in this way did little to help them to learn the concepts being presented. These represent established discourse norms applied by teachers for the purpose of maintaining control of the class. Actively participating in a science lesson was entirely unfamiliar. To do inquiry, the control-oriented norms had to be replaced and the norms of a scientific discourse had to be unpacked. The "things" that the translator describes below include a variety of environmental factors, including ineffective classroom management techniques, threatening and distracting behavior of other students, and poorly implemented classroom technology, all of which worked against the students' ability to engage in science learning. While the students in this study were not participating in disruptive behaviors, they were affected by them:

Researcher: What are some things your teachers do that you don't like?

Translator: All teacher is working with them and understand they don't know much English...the teacher don't have time to work with them sometime.

Researcher: Okay, so do you feel as if your teachers don't spend enough time working on the language with you?

Translator: They feel lonely sometime, they don't want to do.

Researcher: I imagine that's frustrating. Is it frustrating? If the teacher is not helping you and not paying attention?

Translator: They know the other student behavior bad, they know the teacher is busy.

The resultant noise in the classroom became a problem, hindering students already struggling to understand a new language, further limiting their ability to hear and interpret what is being said. Da Po also pointed out that the noise and disruption, on top of the students' limited English abilities, causes them to miss important conceptual understandings. On top of struggling to understand, the students were struggling to hear as well.

This was the established classroom environment in which the authors hoped to facilitate some form of science learning for students. The first complete unit of lessons taught was focused on integration of body systems. The unit plan began with a lab aimed at demonstrating the relationship between exercise, heart rate, and respiration through the use of digital heart rate monitors and a laptop computer. This lab was identified by students, by other teachers, and by the authors as a critical incident during the project as it was an essential first step to developing new norms in which the students would do science. 
Immediately following the lesson, the first author noted in his field notes the impression that it had been quite successful, specifically in that the students were smiling, laughing, and engaging in the science lesson, something that was not observed in any way when they were participating in class with the larger group. Nonetheless, analysis revealed many shortcomings in the lesson, limiting the achievement of desired results, such as participating in scientific discourse, demonstrating meaningful understandings of the concepts addressed, and increased usage of the English language in the science context. Nevertheless, the lesson set a foundation for developing inroads for student acquisition of a scientific discourse, which was eventually made a part of their school science experience.

The lesson began with an overview of the vocabulary for the lab. A vocabulary sheet was provided which included words in English and Karen, the students' first language, with translations obtained from an online Karen dictionary. While field notes indicated that the researcher viewed the overview of vocabulary as effective, analysis of the recorded lesson revealed it to be superficial, only lasting about three minutes with short (less than one minute) revisits throughout the lesson. Only two times during the lesson were the students required to repeat vocabulary words and they were not required to use them in English to answer questions. The next phase of the lesson involved practicing measurement of heart rate by hand and using technology. The labs integrated Pasco force probes, Pasco heart rate monitors, and computer spreadsheets to provide visual access to live data. Each student was then given the chance to use a digital heart rate sensor that measures heart rate through detecting changes in opacity of a part of the body. Students first observed their heart rate by seeing peaks in a graph on the computer monitor each time their heart beat. Next they read their average heart rate as calculated within the computer software. Once students were introduced to the devices and techniques, the group began recording their heart rate and gathering data. This was where the positive engagement, noted before, became evident. When first asked to exercise, students were quite hesitant, nervously laughing as they observed a demonstration. Students were standing very close together, one looking at the floor with her hands folded in front of her. Yet when the activity began, all of the students participated enthusiastically, laughing and smiling throughout the activity. There were still indications of embarrassment, hesitation to continue, especially at the beginning of the trial, but the positive emotions, smiling, laughing, and talking to each other, were far more evident. During focus groups following this lesson and in speaking with one student the following school year, the students described this activity as fun and engaging. This was clearly different from what they had come to expect from school.

Given the literature and its focus on teaching vocabulary to ELLs, the initial approach of this intervention was reasonable to implement and did, in the end, turn out to be an important first step. Nevertheless, at the end of this lesson several things were not intact. Students were not participating in dialogue regarding the lesson, there was little evidence of understanding of the concepts, data was gathered but not used to make decisions, and there was little opportunity for language use. Following their participation in the activity, doing exercise, the students reverted to simply copying what was placed in front of them. Student mistakes and hesitancy to speak were overlooked. In these ways, this lesson became much like their other daily lessons where copying and silence were the norm. This indicated a definite need for a shift in practice to better reflect conceptions of what science and scientific discourse should be. Instances where students did not use the correct words, did not graph correctly, or did not use the language were overlooked. From a science content standpoint, analysis revealed some success. On their lab sheets, students provided answers indicating the beginnings of an understanding of the link between body systems, for example, evidence was found that students were recognizing the connection between exercise, heart rate, and respiration from a focus group discussion. Yet, there were several more indications that the lesson was not effective from a content perspective. Students copied graphs from the computer screen that did not align with the gathered data. Several other answers on the lab sheets represented concepts that were not included in the lab or on the vocabulary sheet; for example, "I drink water when I am tired (Luiza)". 


\section{Shifting Pedagogy, Shifting Discourse}

Analysis of the early lessons revealed the necessity of shifts in the pedagogy of the researcher if shifts in student discourse were to occur. The second lesson identified as a critical incident was on the concept of magnetism, where both pedagogy and students discourse began to shift. It was during these lessons that teaching practices and student responses to them came to more closely resemble a scientific discourse. During a focus group students had indicated that they had not seen or used magnets before, a content topic on the 7th grade district pacing guide. The lesson began by providing several magnets in different shapes and a variety of other materials that were both magnetic and nonmagnetic. Students were given the first period to manipulate the magnets and to familiarize themselves with some magnetic properties. During this time, pertinent vocabulary was introduced to the students. While this still reflects an underlying focus on teaching vocabulary, the pedagogical means implemented for introducing the vocabulary was quite different from that of earlier lessons, shifting to a more conversational means of presenting vocabulary in context. The teacher would ask, "Do you know what these are called?" or just say, "This is a compass." Students would repeat each of the vocabulary words and continue to use the identified term in the lesson. In this way, the words were used and learned as the concepts behind the vocabulary were being explored. The teacher also asked how to say the word in their native language for several of the terms and attempted to pronounce them. This shift in practice was implemented because students had identified in focus groups the importance of social and cultural aspects of this kind in lessons. Vocabulary was no longer presented separate from the lesson, but instead as part of the process of exploring concepts.

The second half of this lesson was spent identifying as a group items that were magnetic or nonmagnetic and placing them in writing onto a two-column table. Students were asked to hypothesize which column the item would be placed in. After each student made his or her hypothesis, the item was tested to identify who was correct. The name of the item was repeated and written onto the table. As the lesson progressed the teacher asked what objects in the room might be magnetic. When a student presented an idea, the group was asked if they agreed, and then tested the object. While the ESL curriculum in the school for this topic focused on the process of cutting out pictures of objects and taping them to a board under labels "Magnetic" or "Non-Magnetic," the authors chose instead to have the students actually test each of the items. Students experienced making and testing hypotheses. The focus was beginning to shift from teaching language to doing science.

The following day began a series of activities designed around the process of making, recording, and testing hypotheses. Students were initially shown two magnets and asked to predict how they would react when placed in different configurations. A picture of the magnets was drawn on a dry erase board or on paper. Students would then draw arrows to represent their hypothesis about how the magnets would react. We immediately tested the configuration to determine who, if anyone, was correct. We repeated several trials of different configurations, integrating the terms north, south, attract, and repel. Each student used each term at least four times during this portion of the lesson. The lesson followed the same pattern for testing the reaction of compasses and iron filings placed near magnets. This was done to introduce the very abstract concept of magnetic fields in a way more concrete and less linguistically demanding than a traditional lecture. The lesson culminated with the creation of a threedimensional model of a magnetic field through suspending a magnet and iron filings in oil. Again, students produced drawings to show their hypotheses prior to making our model (Figure 2).

Important shifts were evident in the ways students were participating across this series of activities. Students used more vocabulary during the course of the lesson. Each student applied new vocabulary a minimum of ten times during the lesson after their initial introduction to the new words. Students also easily identified the different terms on a content exam they were given by the author following the magnet lessons. None of these students missed any magnet related vocabulary questions on this exam. 


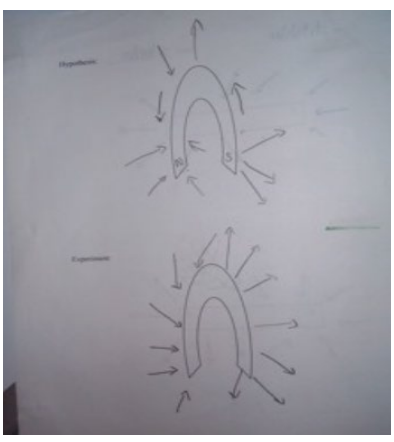

(a)

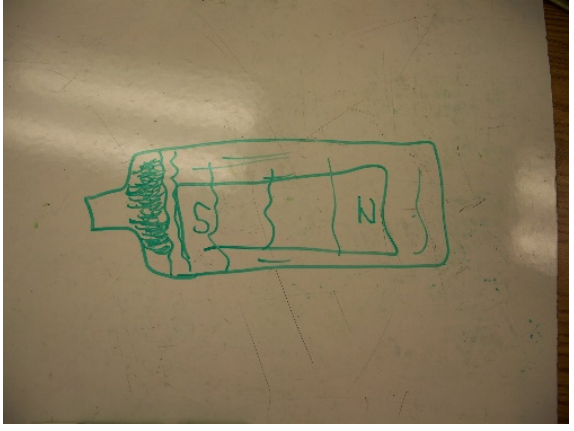

(b)

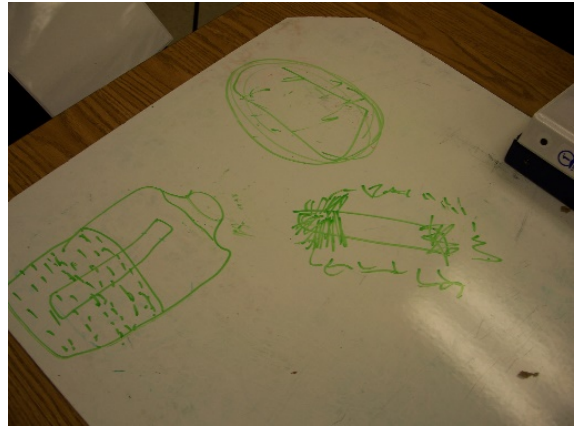

(c)

Figure 2. Students' drawing to show their hypotheses

Beyond increased use of vocabulary from the first critical incident, field notes indicated that aspects of students' science discourse developed through the course of this lesson as well. When students were asked to make predictions regarding the behavior of a compass or magnet placed near another magnet, they provided their predictions, which were recorded and tested, in English using the correct vocabulary. During the initial testing, the predictions were random and inconsistent. Students had developed understanding of the terminology and the appropriate context to use the terms, but did not yet understand the underlying concepts regarding the behavior of magnetic fields or the process of making a hypothesis based on observations. Even with a familiarity with pertinent vocabulary, students continued making random guesses and not informed hypotheses. Yet later in the lesson, data showed a developing understanding of the process of making hypotheses based on previous observations. By the end of the lessons on magnetism, students began to feel comfortable presenting their ideas, although we had not yet established the presentation of the reasoning behind those ideas. Students could now say, "I think this," but did not yet say, "I think this, because...."

Important pedagogical shifts were also evident in this lesson. Based on reflective reviews of lessons and student suggestions in focus groups, attempts were made to be more explicit in provided directions, to speak more slowly throughout the lessons, to model more during lessons, to give more time to understand directions, and to require each student to give a hypothesis each time. Thus, the researcher made conscious efforts to speak slowly and clearly, pausing more often to check for understanding. Students were asked to identify objects they felt would fit into each column and provide an example. This lesson was encouraging in that both pedagogical practice and students' discourse skills had developed substantially, better reflecting the goals and conception of science of the intervention. While student participation and success on the following content exam were encouraging, it was also apparent that further reflexivity and development of practices was necessary to better meet students' needs.

\section{From Silence to Science}

The unit on weather, specifically the lessons on clouds, were chosen as a final critical incident because it was identified by the classroom teacher, ESL teacher, ELL teaching aid, and the authors as an important example of success during the study. Other concepts wrapped into this unit included temperature, pressure, humidity, and precipitation (water cycle), each of which was explored in the group in its own portion of the unit. The cloud lesson, however, did stand out from these other topics for several reasons. Clouds were a topic requested by the students during a focus group discussion on topics they were interested in learning about in science. More than any other lessons, the appropriation of a more scientific discourse became evident, expanding even into the students' home discourse. Students were able to demonstrate this appropriation in a wide variety of ways including; drawing, hypothesis testing, creating digital videos, and making evidence based arguments. The lesson represented a complex interweaving of new concepts, ideas, vocabulary, and scientific processes. As the teaching aid in the room said, "A lot of different concepts went into the clouds lessons. All of that came together." In this lesson, students went into the school courtyard to observe clouds they saw in the sky, sketched their characteristics, and then try to identify them based on descriptions they had researched. 
Instructions in this lesson were much more explicit than previous lessons. Directions were explained, modeled, and revoiced by the students before they began. Students observed, sketched and discussed for 20 minutes and then came together to present their results. Each student showed their picture and described what types of clouds they thought they had seen. One cloud was selected for further discussion. Interestingly, no students initially agreed on what type of cloud it was. This discussion lasted seven minutes, until the end of the period. The clouds were photographed to continue the discussion the next day.

The following day, the students re-presented their hypotheses about the cloud types:

Researcher: What cloud do you think that is? [students look into their notes]

Da Po: I say cirro... [looks up for help]. Cirrostratus.

Researcher: Cirrostratus [writing cirrostratus on white board]

\section{Luiza: Altostratus}

Each student presented their hypotheses in turn. Students searched for pictures on the Internet of the cloud types from their hypothesis and the hypotheses of the other students. They tried to match the picture from outside of the school with a similar picture from their research, while also noting some of the differentiating characteristics of each cloud type. After 20 minutes of research, each student presented what they now believed the cloud to be. All the students changed their mind, deciding that it was in fact a cirrus cloud. They were then asked to explain one characteristic that indicated that it was a cirrus cloud. For example:

Researcher: Can you point to something in the picture that makes it a cirrus cloud? What is different about a cirrus cloud?

\section{Da Po: Ahh, Difference}

Researcher: Yeah, can you point? Why is this cirrus?

Lo Eh: A little cloud.

Students are making observations and making connections between conceptual meanings and new vocabulary. Lo Eh recognized that a bigger cloud could not be a cirrus cloud and may instead be cumulonimbus. This is particularly striking if one notes that two days prior the terms cirrus and cumulonimbus had never been used and likely never heard by this group and relational terms regarding size comparisons had only been introduced a few months prior during a unit covering cells and microscopes. Research has shown that making logical connections of this type in a new language can be particularly challenging for ELLs (Harper \& de Jong, 2004; Kessler \& Quinn, 1995). The lesson concluded with a one-minute review of new vocabulary, precipitation, and the presentation of a question to consider, "What are clouds made of?" This was followed by a similar lesson the next day. Other notable portions of the cloud unit included the creation of a cloud in a bottle and a culminating project in which students created a digital video project identifying various cloud types.

It was quite apparent that this set of lessons was fundamentally different from previous lessons in the intervention. It represented a significant shift in thinking, in designing and planning lessons, and a growing understanding of how to best work with this group of students. Relatively little time was spent explicitly presenting vocabulary, but a substantial increase was evident in the use of vocabulary within the lesson. The focus in this lesson design had shifted to the use of vocabulary to participate in a more scientific discourse, making hypotheses, making observations, and measuring the hypotheses against observed data. Students were answering a question that they themselves had posed, "What kind of clouds do we see?" They were using their own observations to make decisions and changing their 
conceptions based on data they had gathered. They were collaborating and discussing, using new, previously unfamiliar vocabulary to reach their conclusions. Through this process, they were developing mental frameworks for identifying clouds, which they were using to present and test their hypotheses. Students gathered evidence through observations of clouds and internet research in order to make and defend decisions. Students presented new ideas in their hypotheses, provided feedback in trying to convince others of their hypothesis. In presenting their gathered data, the students articulated explanations in English, describing the characteristics that defined the cloud as a cirrus cloud, and reached a consensus that it was in fact a cirrus cloud. Shifts were evident in the way students were participating in the lesson from passive copying of heart rate data to presenting and testing hypotheses and making evidence-based decisions regarding cloud types and from compliantly following directions to exploring and self-expression. Student communication patterns were also shifted from very little speaking to open discussions of the data and from a lack of reasoning in answering questions to "I think...because..." explanatory answers.

Shifts were evident in teaching as well. Lesson focus shifted from presenting vocabulary to using vocabulary in context. A lack of student application of vocabulary shifted to improved opportunities for using English throughout the lesson. In fact, students began to hold one another accountable to this as well. Four times throughout the lesson one student would insist that another group member practice the pronunciation of a word when that student tried to avoid using the word. Brief and unclear directions shifted to explicit and thorough directions resulting in greater risk taking. The cloud lesson was more multimodal in nature. Students used drawing, photography, Internet research, inquiry-based discussion, and digital video to develop their understanding and make connections. Students who had not felt empowered enough to ask to use the restroom or sharpen a pencil, now felt comfortable enough to gather data, make predictions, make decisions based on data, and make arguments all in English. As the school ESL teacher observed:

The way they were naming those clouds, they felt comfortable, so I think that builds their confidence, they were practicing their pronunciation, and seeing pictures, cause all those components are so important, and sometimes the regular classroom teacher can't do that.

Language, it seems, was not the main issue, but instead it was an issue of appropriation of a science discourse and the development of a community of practice in which students are comfortable enough to speak, even though they were not a short time before. Students discussed clouds that they had seen outside of school. Parents indicated that students had taught them cloud names at home. This statement was supported by Lo Eh's mother. In a letter to the parents, translated into the students' home language, the teacher (first author) asked, "Has your child shared with you any of the activities we have done in science class this year?" Lo Eh's mother responded:

My child explained about the cloud and the weather to me. The different names of the clouds and how they form [from response letter translated from Karen].

\section{DISCUSSION}

This study aimed to address the needs, and to tell the story of, a specific group: Southeast Asian students in the northeastern U.S. By looking into individual subgroups of ELLs, we expand the body of knowledge and provide an opportunity to look at better practices for teachers across a variety of different cultural and linguistic subgroups, to better address and inform the needs of ELLs in general, and to identify the specific needs of this particular group. Science lessons designed for the study focused on building meaningful classroom interactions (Rodriguez, 2015) for students by enhancing their classroom discourses and engagement in science activities using technologies and inquiry-based multimodal activities, and by valuing their communities and culture in their learning environment. After the yearlong intervention, participating students were better equipped to engage in a scientific 
discourse. They participated in scientific processes in science class, like presenting hypotheses, gathering data, and making evidence-based decisions. As a community of practice, the teacher and students developed a shared responsibility for practice and learning. The lack of language use evident in the earlier lesson was not evident in later lessons, with levels of vocabulary required within activities adjusted for each student. Some students were required to provide an explanation for their hypothesis and their conclusions, while others needed only to provide their hypothesis. Still, all students were required to speak and to participate in the discussion throughout the lesson. These were purposeful decisions based on teacher reflection that lead to increased engagement and language use.

Where prior participation in science class was observed as passive and non-disruptive, aimed to not draw attention from their teachers, later participation saw participants engaged in a variety of ways in inquiry-based multimodal activities. They were initially left adrift and confused while their classroom teachers' time was absorbed by other students. Their eventual engagement in science resulted in the appropriation of a more scientific discourse through their participation. They encountered initial disorientation, then acclamation, and then appropriation of specific linguistic and academic science norms throughout the course of the year-long intervention.

During initial critical incidents we observed basic emotional and non-verbal cues, which confounded our teaching and analysis as students continued to actively participate in explicit activities. Smiles and laughing during their participation pointed to a level of engagement very different from the passive silence prior and in concurrent classes ELL students encountered during their day. In later lessons students began to engage at a more scientific level, stating hypotheses, conducting research, and making evidence-based decisions.

Hos (2020) asserted that there is a need to develop a specialized curriculum for refugee ELL students' development of English language proficiency and disciplinary learning. The current study provides evidence to support the claim that specialized curriculum helped them develop their scientific discourse skills and engagements in science classrooms. Especially, multimodal strategies that were implemented allowed for greater engagement in some cases by reducing linguistic demands on students through providing different means to demonstrate and participate in learning other than a verbal mode. The finding also supports a previous study that multimodal components in educational technology enabled ELL students to learn with greater flexibility (Green, 2005). Modes like drawing, writing, acting, and creating digital video were all implemented throughout the intervention. The multimodal aspects of the lessons helped to provide a foundation for the development of a scientific discourse that we were working towards, allowing students to access and apply the discourse skills that they brought to the class.

Digital technology provided a means of incorporating these multiple modalities. The technological focus in this study differed from previous studies on technology implementation for English learners (Cummins, 2001; Kang \& Dennis, 1995) in that it did not view technology primarily as a means of presenting and assessing vocabulary, but instead focusing on technology as a way to reduce linguistic demands, to foster meaningful engagement, and to foster development of a community of practice as described by Liaw (1997). It was when technology was used in these ways that students identified it as beneficial and engaging during focus group discussions, which could result in enhancing students' confidence and motivation in learning (Ahmadi \& Reza, 2018). Tools like digital video and photography allowed students to access content in multimodal ways like writing, drawing, speaking, and acting, while reducing linguistic demands through students' ability to practice and re-record spoken portions of video. Implementation of technology increased engagement only when it provided opportunities for students to communicate and interact. These findings support the notion that technology used in these ways can be a powerful tool in this and similar contexts (Ahmadi \& Reza, 2018; Green, 2005; Liaw, 1997; Lopez, 2010). 
Inquiry-based science practices were integrated throughout this study in conjunction with technological tools. Inquiry-based science activities from later portions of the intervention specifically prescribed students' use of hypotheses and student generated questions, which led to more engagement for students than earlier confirmation level inquiry activities. During this type of minds on activity, students showed significantly more engagement than in previous inquiry activities. When compared to the early confirmation and traditional lessons, the students were more enthusiastic in performing their experiments, they participated in more discussion in both their native language and in English, and, on the following content exam, demonstrated higher science achievement on this topic. This result echoed findings from previous studies that inquiry-based science activities promoted ELL students' communication skills and confidence in classroom discourses and interactions with peers (Lee, 2005; Oliveira et al., 2019). Not only that, but we also found that the participating students demonstrated a greater conceptual understanding of the material that was presented in an inquiry-oriented fashion as measured in formative and State level assessments.

Throughout the intervention, the group developed into a learning community where students developed confidence in their ability to participate in science lessons. Students felt more comfortable within this community of practice and consequently began to speak more. The strategies implemented allowed them to speak in context in an environment that was comfortable for them. The development of the community of practice was closely tied to the students' view of their teacher. Students felt more comfortable in this environment because they were treated differently than they were by other teachers. This study provides ample evidence of refugee ELL students' engaging in progressive learning of science and new language through a close interaction with their teacher who also demonstrated a continuous development in his teaching practice with this particular group of students. This study shed light on the importance of building the community of practice where students feel valued and heard of their voices, and their culture is respected. Within the community, silenced students became more vocal and confident in learning science. Thus, this study contributes to the body of literature by presenting empirical evidence to support refugee ELL students' positive development in a public school system in the U.S.

\section{CONCLUSION}

This study holds several implications for educational research and practice. First, the study demonstrated how refugees ELL students developed their discourse skills and classroom engagements through the yearlong intervention designed to build trust between teacher and students by sharing responsibility for practice and learning, to involve inquiry-based science activities, and to value students' communities and culture. Those factors helped the students to interact with teachers and peers and to create positive learning outcomes.

Second, inquiry-based multimodal activities should be emphasized to shift students' passive participation to active one. This study showed that providing more multimodal opportunities to express themselves helped students to overcome their fears in classrooms and to build their pride in their learning outcomes.

Third, it is important to develop a learning community for the students in order to provide safe and comfortable learning environments. In the learning environments grounded in values of their culture and own community, students felt more comfortable and valued by their peers and teachers, which could help them to begin to speak in class. Ngo et al. (2018) suggested to involve students' communities and kinships in creating their learning environments especially for South Asian students (Ngo et al., 2018). However, in the current study, those relations were not fully considered when designing the intervention. Thus, we suggest a future study exploring how to involve refugee ELL students' communities, parents, and their other kinships into designing learning environments and science curriculum. 
Author contributions: All authors were involved in concept, design, collection of data, interpretation, writing, and critically revising the article. All authors approve final version of the article.

Funding: The authors received no financial support for the research and/or authorship of this article.

Declaration of interest: Authors declare no competing interest.

Data availability: Data generated or analysed during this study are available from the authors on request.

\section{REFERENCES}

Ahmadi, D., \& Reza, M. (2018). The use of technology in English language learning: A literature review. International Journal of Research in English Education, 3(2), 115-125. https://doi.org/10.29252/ijree.3.2.115

Arkoudis, S. (2003). Teaching English as a second language in science classes: Incommensurate epistemologies? Language and Education, 17(3), 161-173. https://doi.org/10.1080/09500780308666846

August, D., \& Hakuta, K. (Eds.). (1997). Improving schooling for language-minority children: A research agenda. National Academy Press.

August, D., Branum-Martin, L., Cardenas-Hagan, E., \& Francis, D. J. (2009). The impact of an instructional intervention on the science and language learning of middle grade English language learners. Journal of Research on Educational Effectiveness, 2(4), 345-376. https://doi.org/10.1080/19345740903217623

Banchi, H., \& Bell, R. (2008). The many levels of inquiry. Science and children, 46(2), 26-29.

Bransford, J. D., \& Donovan, M. S. (2005). Scientific inquiry and how people learn. In M. S. Donovan, \& J. D. Bransford (Eds.), How students learn: History, mathematics, and science in the classroom (pp. 397-420). National Academy Press.

Cosentino de Cohen, C., Deterding, N., \& Clewell, B. C. (2005). Who's left behind? Immigrant children in high- and low-LEP schools. Urban Institute. https://doi.org/10.1037/e723132011-001

Creswell, J. W. \& Poth, C. N. (2018). Qualitative inquiry \& research design: Choosing among the five approaches. (4th ed.) Thousand Oaks, CA: Sage Publications.

Cummins, J. (2001). Magic bullets and the fourth grade slump: Solutions from technology? NABE News, 25(1), 4-6.

Delpit, L. (1995). Other people's children: Cultural conflict in the classroom. New Press. https://doi.org/10.2307/358724

Gay, G. (2000). Culturally responsive teaching: Theory, research, and practice. Teachers College Press.

Gee, J. P. (2005). Language in the science classroom: Academic social languages as the heart of school-based literacy. In R. Yerrick \& W-M. Roth (Eds.), Establishing scientific classroom discourse communities: Multiple voices of teaching and learning research (pp. 19-37). Lawrence Erlbaum Associates.

Glasgow, N. A., Cheyne, M., \& Yerrick, R. K. (2011). What successful science teachers do: 75 research-based strategies. Corwin Press Inc.

Green, T. (2005). Using technology to help English language students develop language skills: A home and school connection. Multicultural Education, 13(2), 56-59.

Harper, C., \& de Jong, E. (2004). Misconceptions about teaching English Language Learners. Journal of Adolescent \& Adult Literacy, 48(2), 152-162. https://doi.org/10.1598/JAAL.48.2.6

Hos, R. (2020). The lives, aspirations, and needs of refugee and immigrant students with interrupted formal education (SIFE) in a secondary newcomer program. Urban Education, 55(7), 1021-1044. https://doi.org/10.1177/0042085916666932

Iddings, A. C. D., \& Jang, E. Y. (2008). The mediational role of classroom practices during the silent period: A new-immigrant student learning the English language in a mainstream classroom. TESOL Quarterly, 42(4), 567-590. https://doi.org/10.1002/j.1545-7249.2008.tb00149.x

Janzen, J. (2008). Teaching English language learners in the content areas. Review of Educational research, 78(4), 1010-1038. https://doi.org/10.3102/0034654308325580

Jarrett, D. (1999). The inclusive classroom: Teaching mathematics and science to English-language learners. Northwest Regional Educational Laboratory.

Jiménez-Castellanos, O. H., \& García, D. (2017). School expenditures and academic achievement differences between high-ELLperforming and low-ELL-performing high schools. Bilingual Research Journal, 40(3), 318-330. https://doi.org/10.1080/15235882.2017.1342717

Kang, S. H., \& Dennis, J. R. (1995). The effects of computer-enhanced vocabulary lessons on achievement of ESL grade school children. Computers in the Schools, 11(3), 25-35. https://doi.org/10.1300/J025v11n03_04

Kessler, C., \& Quinn, M. E. (1995). ESL and science learning. In J. A. Crandall (Ed.), ESL through content-area instruction (pp. 5384). ERIC Clearinghouse.

Koehler, M., \& Mishra, P. (2009). What is technological pedagogical content knowledge (TPACK)? Contemporary issues in technology and teacher education, 9(1), 60-70.

Lee, O. (2005). Science Education with English Language Learners: Synthesis and Research Agenda. Review of Educational Research, 75(4), 491-530. https://doi.org/10.3102/00346543075004491 
Lee, O., \& Buxton, C. A. (2013). Teacher professional development to improve science and literacy achievement of English language learners. Theory Into Practice, 52(2), 110-117. https://doi.org/10.1080/00405841.2013.770328

Lee, O., \& Luykx, A. (2007). Science education and student diversity: Race/ethnicity, language, culture, and socioeconomic status. In S. K. Abell \& N. G. Lederman (Eds.), Handbook of research on science education (pp. 171-198). Lawrence Erlbaum Associates, Inc.

Liaw, M. L. (1997). An analysis of ESL children's verbal interaction during computer book reading. Computers in the Schools, 13(3), 55-73. https://doi.org/10.1300/J025v13n03_06

Llosa, L., Lee, O., Jiang, F., Haas, A., O'Connor, C., Van Booven, C. D., \& Kieffer, M. J. (2016). Impact of a large-scale science intervention focused on English language learners. American Educational Research Journal, 53(2), 395-424. https://doi.org/10.3102/0002831216637348

Lopez, O. S. (2010). The digital learning classroom: Improving English language learners' academic success in mathematics and reading using interactive whiteboard technology. Computers $\mathcal{E}$ Education, 54(4), 901-915. https://doi.org/10.1016/j.compedu.2009.09.019

Lynch, S. (2000). Equity and science education reform. Lawrence Erlbaum. https://doi.org/10.4324/9781410605139

McBrien, J. L. (2005). Educational needs and barriers for refugee students in the United States: A review of the literature. Review of Educational Research, 75(3), 329-364. https://doi.org/10.3102/00346543075003329

Michaels, S., \& O'Connor, M. C. (1990). Literacy as reasoning within multiple discourses: Implications for policy and educational reform. Paper presented at the meeting of The Council of Chief State School Officers 1990 Summer Institute.

Ngo, B., Dyke, E., \& LoBello, J. (2018). Connecting as "family" in educative relationships: Insights from a media program serving Hmong immigrant youth. Urban Education, 53(9), 1126-1153. https://doi.org/10.1177/0042085917697202

Noddings, N. (1997). Caring and interpersonal reasoning. Thinking for ethical action in families and communities, 40-48.

Oliveira, A. W., Weinburgh, M., McBride, E., Bobowski, T., \& Shea, R. (2019). Teaching science to english language learners: Current research and practices in the field of science education. In L. C. de Oliveira (Ed.), The handbook of TESOL in K-12 (pp. 277-290). Wiley-Blackwell. https://doi.org/10.1002/9781119421702.ch18

Portes, A., \& Rumbaut, R. G. (2001). Legacies: The story of the immigrant second generation. University of California Press.

Rodriguez, A. J. (2015). What about a dimension of engagement, equity, and diversity practices? A critique of the next generation science standards. Journal of Research in Science Teaching, 52(7), 1031-1051. https://doi.org/10.1002/tea.21232

Rodriguez, A., \& Kitchen, R. S. (Eds.). (2005). Preparing prospective mathematics and science teachers to teach for diversity: Promising strategies for transformative action. Erlbaum.

Tan, E., \& Barton, A. C. (2010). Transforming science learning and student participation in sixth grade science: A case study of a low-income, urban, racial minority classroom. Equity $\mathcal{E}$ Excellence in Education, 43(1), 38-55. https://doi.org/10.1080/10665680903472367

Villegas, A. M., Saizde La Mora, K., Martin, A. D., \& Mills, T. (2018, April). Preparing future mainstream teachers to teach English language learners: A review of the empirical literature. The Educational Forum, 82(2), 138-155. https://doi.org/10.1080/00131725.2018.1420850

Zhou, M., \& Bankston III, C. L. (2000). The biculturation of the Vietnamese student. ERIC Clearinghouse on Urban Education, 152, 1-7. 